\title{
Estudos de elites políticas e as bases das multinotabilidades no Brasil
}

Eliana Tavares dos Reis e Igor Gastal Grill

Introdução

Nos empreendimentos inaugurais e mais sistemáticos no âmbito das ciências sociais, as discussões declaradamente apresentadas como dedicadas "às elites" debruçaram-se sobre segmentos e domínios políticos. Em decorrência, na divisão do trabalho científico - que, como enfatizou Bourdieu (2004), acaba correspondendo a uma divisão real do real -, a referida categoria (não raro tomada de modo substancialista) se constituiu em objeto privilegiado da ciência política, firmando-se espontaneamente como sinônimo de elite política e, inclusive, exercendo papel não negligenciável nas estratégias de institucionalização dessa área de conhecimento ${ }^{1}$. Apenas mais recentemente pesquisadores de outros campos e vertentes têm operado descentramentos daquele quase monopólio disciplinar, sobretudo flexibilizando os segmentos investigados e os modelos de análise mobilizados. E essas reflexões têm oportunizado redimensionar o tratamento dos grupos politicamente dirigentes ${ }^{2}$.

Seguindo essas trilhas, propomos neste artigo a ordenação de três bases de multinotabilização das elites políticas no Brasil. Apoiados em resultados de pesquisas inscritas no campo de estudos sobre profissionais da política, que realizamos em diferentes fases das nossas trajetórias acadêmicas, discutimos o peso: (1) dos grupos

1. Ver Braud (2001) e Coradini (2016).

2. Para uma discussão mais detalhada, consultar Reis e Grill (2016). 
familiares de origem, como gênese da aquisição de patrimônios (econômico, cultural, social e simbólico), de apetências e competências; (2) dos trajetos escolares, militantes e profissionais, nos quais podem ser acrescidos ou dilapidados, acumulados ou conquistados, recursos variados, entre eles redes de relações, linguagens e habilidades práticas; (3) da produção de bens simbólicos como explicitação de disposições e oportunidades de tomadas de posição sobre concepções de sociedade, política e cultura compartilhadas e disputadas.

Essas dimensões se complementam para a produção de atributos e trunfos mobilizáveis nas lutas políticas. Assim (e independente da forma de definição do universo empírico ou do "recorte da pesquisa”), a apreensão de suas características multidimensionais e interseccionadas potencializa a investigação extensiva e intensiva dos princípios de funcionamento, seleção e hierarquização dos domínios políticos, dos condicionantes e lógicas de atuação dos agentes, bem como dos processos de legitimação que incidem na composição das "elites políticas".

Inicialmente, discutimos aqui questões relativas às análises de elites, retomando brevemente algumas abordagens e encaminhamentos, sobretudo conceituais e metodológicos, que consideramos pertinentes ao tratamento de universos, lógicas e práticas reconhecidas como políticas ${ }^{3}$. Não somos panorâmicos na exposição de discussões teóricas e temáticas, nem retomamos com fôlego uma sucessão de textos consagrados visando, verbi gratia, estabelecer convergências de filiações e genealogias de escolas, estudos e autores. Mas também não ignoramos um conjunto de empreendimentos intelectuais aos quais reputamos o lugar de referência aos nossos trabalhos, em especial porque colaboram à inteligibilidade de determinados fenômenos sociais.

E, em seguida, tomando por base investigações específicas, detemo-nos sobre cada uma das dimensões supracitadas e suas inter-relações, com o intuito de examinar as bases das multinotabilidades alcançadas por determinados agentes e as potencialidades heurísticas de certos esquemas analíticos para estudos desse tipo.

\section{Alguns encaminhamentos analíticos}

A afirmação dos estudos de elites políticas é certamente tributária de, no mínimo, três processos interdependentes: (i) de formação do Estado moderno, dos profissionais dedicados a viver da e para a vida pública e das organizações partidárias como forma legítima/inelutável de mobilização eleitoral (Weber, 1987); (ii) de autonomização da ciência política como disciplina acadêmica, mediante a afirmação de "especialistas"

3. Sem desconsiderar uma definição mais alargada, que abarca relações e formas de atuação não restritas a determinadas esferas institucionais e princípios oficiais. 
com certos perfis, reivindicando objetos, métodos e teorias específicas, e logrando espaços institucionais voltados à sua produção (Cohen et al., 2009; Favre, 1989); (iii) e de edificação progressiva (e sempre atualizada) de uma linhagem consagrada de autores e debates, que se impõe (muitas vezes irrefletidamente) às discussões que se dedicam aos indivíduos situados no ápice de uma estrutura de posições referentes a âmbitos distintos de exercício do poder, como ministérios, parlamentos, burocracias, partidos etc. (Grynszpan, 2016; 1999; Reis e Grill, 2016; Coradini, 2016).

A questão é nos situarmos numa agenda de pesquisas sobre elites políticas sem sucumbir à tradição de transformar relações em objetos estáticos, reificados, em detrimento de uma abordagem dinâmica, relacional, processual (Elias, 1994). Quer dizer, rompendo, por um lado, com a tendência ao retorno rotinizado à linhagem fundadora (exercício meramente exegético de construção genealógica) que, quando associado a uma ideia substancializada de poder, resulta na percepção de indivíduos como "personalidades criadoras", cujo protagonismo histórico alguns analistas chegam até a reverenciar e, "num cantinho de sua alma, talvez até se identifiquem" (Idem, p. 75). E, por outro lado, com a atribuição a certas formações sociais ou humanas de uma anima collectiva, "alma própria que transcende as almas individuais" (Idem, p. 15), substancializando coletividades ("elite", "burguesia", "classe dominante", "regime", "Estado", "sociedade", "partidos" e assim por diante), consideradas como entidades supraindividuais anônimas e as antropomorfizando (como se fossem entidades dotadas de estratégias e fins conhecidos).

Para ponderar sobre o conjunto de fatores interligados e interdependentes interveniente nos processos de afirmação política, pode-se retomar brevemente a polarização entre, de um lado, a tradição americana de preocupações com as "elites políticas" e, de outro, a versão das pesquisas francesas. Nos Estados Unidos foi principalmente a partir da década de 1930 que houve a "afirmação do elitismo como teoria política e sociológica relevante e, por consequência, de elevação de seus formuladores [Mosca, Pareto e Michels] ao panteão das ciências sociais" (Grynszpan, 2016, p. 51). Já nos anos de 1950/1960, o debate em torno das "elites" foi renovado, com destaque às formulações (e confrontações) de Charles Wright Mills e de Robert Dahl (Coradini, 2016; Reis e Grill, 2016). No entanto, a partir dos anos de 1970, houve um arrefecimento das apropriações dos elitistas na ciência política e a escalada da rational choice theory - que mais recentemente já é alvo de críticas direcionadas aos seus fundamentos epistemológicos e sua validade científica -, assim como tem ocorrido uma ascensão de interpretações mais históricas e sociológicas à análise dos fenômenos políticos (Ruget, 2009).

Afora as transformações das perspectivas dominantes de análise, de um modo geral, observa-se na tradição americana a importância dos papéis profissionais e dos 
procedimentos propriamente políticos de seleção, bem como as afinidades entre as exigências da profissão política e determinados saberes profissionais. O que pode ser confrontado com a "escola francesa", atenta aos indicadores de posição social do "pessoal político", aos mecanismos de delegação e às homologias entre representantes e representados. Essas distinções são relacionadas com os condicionantes dos processos de institucionalização da ciência política e à história política próprios desses países, como o peso do bipartidarismo, da estrutura compósita dos partidos, da influência dos grupos de interesse, entre outros, no primeiro; e à robusta disciplina partidária, estabilidade do perfil na alta administração pública e forte simbologia política do idioma da classe, entre outros, no segundo (Sawicki, 1999).

Para a França foi observado o movimento no sentido inverso àquele norte-americano. Quer dizer, sequiosos em romper o vínculo com os cursos de direito, a partir dos anos de 1970, os cientistas políticos franceses se apropriaram das problemáticas sociológicas e deflagraram uma espécie de "canibalização" da ciência política pela sociologia política, generalizando as referências a Émile Durkheim, Norbert Elias e Pierre Bourdieu (Cohen et al., 2009, p. 25). Sobretudo a partir da década de 1980, aos parâmetros sociológicos foram aliadas preocupações com a gênese dos processos históricos. O que significou o direcionamento do olhar às invenções e transformações do Estado, de grupos, categorias, lógicas de politização, repertórios coletivos, tecnologias de mobilização política, enfim, de instituições no sentido ampliado que a ciência social francesa consagrou e que a sociologia política batizou como sócio-história do político (Idem).

Com base nas pesquisas realizadas no âmbito dessa sociologia política, um conjunto de variáveis e indicadores mobilizados se mostraram pertinentes ao tratamento da diversidade de origens sociais das lideranças políticas (origem geográfica, características do grupo familiar, profissão, percurso escolar, inserções sociais prévias à carreira política etc.), aos padrões de carreiras (sequência de cargos, trajetos de postos políticos ocupados no espaço político etc.) e das identificações políticas/ideológicas, quer dizer, concepções concernentes à política e à sociedade.

$\mathrm{Na}$ ciência política brasileira, a proeminência na importação das abordagens da primeira tradição, de cunho mais internalista, refletiu-se na centralidade conferida às instituições (mesmo que mal instituídas), articulando regras, procedimentos e funcionamentos internos às organizações com a localização de estratégias racionais de escolhas e/ou com fatores historicamente sedimentados (vertentes de neoinstitucionalismos). Eventualmente alguns analistas incorporaram variáveis mais sociográficas, no entanto com alcance explicativo bem direcionado ${ }^{4}$. Recentemente

4. Como é o caso do cotejamento de dados sobre ocupação, patrimônio e escolarização, para demonstrar 
é que cientistas políticos passaram a incorporar consistentemente variáveis sociais e históricas aos seus trabalhados, recorrendo aos achados da "escola francesa". Com isso, ganharam algum relevo os estudos sobre carreiras políticas, fundamentados na exploração de dados biográficos e dos critérios de recrutamento das elites políticas brasileiras, fundamentalmente parlamentares ${ }^{5}$.

O que está em pauta é o esforço em renunciar às dualidades que opõem e fundamentam escolhas metodológicas: internalismo (ênfase nas variáveis e indicadores atinentes à hierarquização do espaço político) versus externalismo (priorização das bases sociais de recrutamento); perspectivismo (foco nas representações e sentidos dos agentes) versus objetivismo (tratamento dos condicionantes estruturais e dos constrangimentos externos que agem sobre os protagonistas). Grifa-se ainda a comum desconexão (nada frutífera) entre as compreensões, de um lado, das lógicas de seleção política decorrentes de processos de longa duração (reconstituídos diacronicamente em suas regularidades e variações) e, de outro, das disputas travadas em momentos específicos (esmiuçados na sincronia dos acontecimentos). E, conjugado a isso, a aposta na necessidade de superação das divisões disciplinares (principalmente entre sociologia, antropologia, ciência política e também a história) e subdisciplinares, nas quais a especialização na análise de universos como se fossem segmentados ("família”, “escola”, “engajamentos militantes”, "profissões”, "partidos”, "parlamento", "discursos" etc.) é evidentemente fundada em disputas pelo monopólio do saber acerca das regras de funcionamento relativas a escaninhos da vida social, contribuindo, pois, à produção de disjunções fictícias em detrimento da possibilidade de apreensão das múltiplas e irremediáveis interdependências que formam as maleáveis configurações sociais.

Nesse sentido, podemos ressaltar a precariedade das fronteiras que delimitam os espaços e os registros de atuação de agentes mais ou menos especializados em determinadas atividades. $\mathrm{O}$ que instiga a examinar como as chances de circulação e afirmação de agentes, com determinadas propriedades e trunfos, são oportunizadas pelo caráter vulnerável das divisas entre domínios de atuação e lógicas de intervenção, sobretudo políticas e culturais, no Brasil. Em nossas pesquisas temos apontado que isso guarda relação com o peso das estratégias de importação e certificação de modelos exógenos ("estrangeiros") nas lutas autóctones, interferindo, entre outros aspectos, na configuração de um espaço compósito, no qual são precários os limites institucionais, que apresentam graus variados e frágeis de institucionalização (perceptível não só em

correlações significativas entre a base social dos parlamentares e o espectro de forças partidárias e ideológicas, que justificariam uma avaliação positiva dos partidos (Rodrigues, 2002).

5. Com destaque para os trabalhos de Coradini (2001), Marenco (2004) e Perissinoto e Miriade (2009), que mobilizam esquemas analíticos significativamente distintos entre si. 
tempos de crise). Nesse caso, propomos pensar em termos de dominios amoldados por uma multidimensionalidade de princípios (ideológicos, burocráticos, éticos, estéticos, religiosos, políticos, profissionais etc.) orientadores das práticas. Em realce, evidenciamos a ascendência resistente das relações pessoais e atributos personalizados como posses complementares entre si e indispensáveis à multinotabilização de agentes nos distintos domínios, assim como às possibilidades de trânsito entre eles ${ }^{6}$.

Tendo em vista o que foi dito, tem-se que as chances de inserção e ocupação de posições "de elite" relacionam-se à concentração de oportunidades de poder e ativação de recursos com validade flexível em distintos domínios. Principalmente, podemos considerar as condições de acumulação de recursos herdados (em especial no meio familiar) e os adquiridos (sobretudo no decorrer de biografias de investimentos escolares, militantes e profissionais). Tais são os eixos que procuramos detalhar ao longo da próxima discussão.

\section{As bases das multinotabilidades das elites políticas brasileiras}

Como já mencionamos, o debate ora proposto é desdobrado em três momentos, nos quais expomos resultados de pesquisas que fizemos sobre reprodução de "famílias de políticos"; carreiras políticas, profissionais e intelectuais de militantes (a maior parte profissionalizados na política); e peso da produção de bens simbólicos entre parlamentares. Sublinhamos o indispensável cotejamento de variáveis e indicadores sobre origens sociais, trajetos escolares, militantes e políticos, modalidades de atuação e formas de apresentação/legitimação da "vocação política". Com base nisso, delineamos padrões de seleção e de especialização políticas vigentes no Brasil. Acreditamos que eles são expressivos das lógicas de funcionamento, dos princípios de hierarquização/seleção e dos processos de legitimação que incidem para a composição das "elites políticas".

\section{A "família" como via de acesso às posições políticas}

Muitos agentes que conquistam as posições mais bem alocadas nos domínios políticos (assim como em outros) contaram com a transmissão de espólios (materiais e simbó-

6. Sobre a pertinência de pensarmos valendo-nos da ideia de domínios quando impera uma configuração de maior indiferenciação das esferas sociais, ver Reis e Grill (2016). Para o uso feito da noção de notável em situações de profissionalização política, ver a introdução da revista Politix (2004) dedicada ao tema. Sobre a necessidade de pensarmos em termos de múltiplas e amalgamadas notabilidades, decorrentes de um contexto em que prevalecem a multiposicionalidade dos agentes e a multidimensionalidade nas fontes de créditos personificados, ver novamente Reis e Grill (2016). 
licos) mais ou menos diversificados, mas de algum modo congruentes à formação de gostos, ao domínio de códigos e à posse de recursos (econômicos, sociais, políticos, culturais etc.) passíveis de serem mobilizados (direta ou indiretamente) no decorrer de investimentos (não necessariamente planejados ou unilineares) em direção a "destinos" políticos (nem sempre inevitáveis ou percebidos como uma "meta").

A questão que se coloca de antemão é a de não tomar a "família" como algo que decorre de uma existência natural ou linear, mas como lugar de concentração e "concertação" de meios - assim constituído graças à convergência de processos de ordem ritual, técnica, simbólica e prática proporcionada por várias instituições, como o Estado, a Igreja etc. (Bourdieu, 1996). Seguindo as ponderações de Bourdieu (1996; 1994), podemos considerá-la como a primeira fonte de produção de vereditos positivos ou negativos, ou seja, é mediante as disposições herdadas na socialização familiar que os indivíduos desenvolvem seus sentidos de estima ou de estigma social, principalmente aprendem a valorizar e reconhecer (desconhecendo as condições sociais de produção) quais são os atributos desejáveis e suas condições de acessá-los (ou não). É por esse intermédio que se entendem os mecanismos sociais de legitimação e de reprodução de uma ordem desigual, cujo ápice é a certificação institucional de "qualidades", "aptidões", "dons" socialmente constituídos. Nesse trabalho coletivo, a "unidade doméstica" é regida por lógicas de integração, fusão e coesão, que se traduzem em estratégias de produção, gestão, transmissão e ampliação de recursos variados e com múltiplas funções (educativas, afetivas, sexuais, econômicas, culturais, políticas, etc.).

Portanto, além de "berço" da aquisição de um sistema de disposições que define princípios de visão e classificação do mundo social, a família é também uma instância catalisadora e (re)distribuidora de um patrimônio coletivo, exigindo empenhos dos seus membros na adoção de estratégias de reprodução com vistas à sua continuidade. Essa definição não é divergente da possibilidade de pensá-la como empresa multidimensional de dominação (Weber, 1987), operando registros contrastantes e configurando uma divisão mais ou menos complexa e demarcada de papéis prescritos em distintos domínios. Não sendo esse trabalho estático e sendo seus resultados imprevisíveis, lembramos que as famílias passam por adaptações constantes, no mínimo, por conta das sucessões geracionais e das transformações históricas e sociais mais amplas. Assim, podem ser pensadas processualmente, recuperando as formulações de Elias (1993), como sucessões configuracionais desenhadas por elos de interdependências funcionais existentes entre seus componentes, e incessantemente redesenhadas como efeito inesperado das tensões que emergem da coexistência entre forças reticulares (alianças e rivalidades) internas e externas.

Nos estudos de famílias com diversos componentes nas elites políticas e cujos membros recorrentemente ocupam postos ao longo de gerações - o que incide na 
própria identificação como "famílias de políticos" - é importante observar, além da persistência/continuidade, o potencial de retenção de notoriedades, pois informa seu lugar em cadeias de ajudas mútuas e de confianças recíprocas. Os lucros auferidos de uma "honra coletiva" são inseparáveis de múltiplos e robustos rendimentos nos domínios políticos. Isso porque os vínculos de parentesco contrabalanceiam os fatores de incerteza e insegurança que definem a concorrência no jogo político (Wolf, 2003). Logo, o pertencimento familiar pode comportar uma dimensão da estima social (prestígio público e dignidade do nome), que os agentes podem reconverter em recursos e trunfos políticos em situações de disputas eleitorais e vice-versa (Briquet, 1992).

É bom lembrar que, de fato, quanto mais o jogo político tem feições "oligárquicas", maior será o peso e a reprodução direta desses agrupamentos no jogo - que podem chegar a constituir "dinastias" - e, quando esse jogo adquire traços "democráticos", quanto mais diversificado e matizado com intermediações ele é, menos favoráveis são as condições dessa reprodução. $\mathrm{O}$ que não significa dizer que a afirmação de uma dinâmica mais especializada e institucionalizada de competição política iniba ou interrompa a dedicação de gerações de famílias à política. Assim como não há uma coincidência entre as propriedades sociais das famílias e modelos de organizações políticas com as lutas por persistência e reprodução no jogo político. A pesquisa realizada sobre as "heranças políticas" no Rio Grande do Sul demonstrou que os intercruzamentos de lógicas e práticas familiares e políticas perseveram em distintas configurações históricas e perfis sociais e ideológicos, mesmo que com redefinições de conteúdos, de critérios de ocupação de posições políticas privilegiadamente situadas e de características sociais dos "grupos familiares" (Grill, 2008).

$\mathrm{Na}$ investigação supracitada, foram feitas 43 entrevistas em profundidade, etnografias de processos eleitorais, localização de genealogias, biografias e memórias, entre outros materiais que permitiram sistematizar informações para 167 agentes, com origens em 33 famílias reconhecidas como sendo "famílias de políticos", que ao longo de geraçôes têm componentes com carreiras políticas relativamente sólidas. Cada uma delas tem em média cinco membros com destaque político, distribuídos entre duas a quatro gerações. No entanto, é importante esclarecer que essa afirmação como "família de políticos" não depende somente da ocupação bem sucedida de cargos políticos, mas de um trabalho coletivo de consagração, deflagrado inclusive por meio de posições ocupadas em outros domínios sociais, do uso de modalidades variadas de intervenção política (não necessariamente relacionados à arena eletiva) e dos reconhecimentos conquistados (sem deixar de falar da detração dos adversários).

$\mathrm{Na}$ análise dos dados, foram examinadas as posições sociais de origem das famílias no período precedente ao ingresso nas disputas eleitorais. Para tanto, localizaram-se as atividades desempenhadas pelos ascendentes (principalmente os pais) do primeiro 
político, situando também o período (década) em que ele estreou nas competições eletivas. Do mesmo modo, foram correlacionadas informações sobre: ocupação; grau de escolarização; títulos escolares conquistados e instituições de ensino pelas quais passaram; cargos e idade de ingresso na carreira de postos públicos e eletivos; número de candidaturas; tempo de carreira em cargos eletivos e administrativos; todas para o conjunto dos políticos pertencentes às famílias investigadas. E ainda, como dimensão imprescindível de análise, atentou-se às concepções acerca da política e aos trunfos disponíveis à consagração da família e dos antepassados.

Com isso, foi possível identificar três tipos de conexão entre perfis e estratégias de reprodução familiar como vias de acesso a atividades políticas: um que podemos definir como mais "tradicional", uma espécie de padrão clássico dos notáveis que se concebem como "vocacionados à coisa pública"; o segundo traz a marca da ascensão social do grupo familiar de origem, no qual os investimentos são no sentido de acumular recursos com vistas à afirmação e escalada social e política; e o terceiro explicita a diversificação social, escolar e das "missões" conduzidas pelos agentes que formam um padrão militante de atuação política. $O$ Quadro 1 sistematiza essas características.

No que pese sintetizarem regularidades e contrastes verificados em uma configuração regional específica (Rio Grande do Sul), há um conjunto de investigações que lidaram com questões com as quais dialogamos constantemente e revelaram padrões semelhantes para outros estados da federação ${ }^{7}$. Com efeito, pesquisas desse tipo nos permitem captar a forte vinculação do conjunto de recursos acumulados, propensões inculcadas à intervenção, vínculos mobilizáveis a partir do meio familiar na sua intersecção com os destinos de agentes que se inscrevem em domínios políticos. Investir em determinados títulos escolares (obtidos em certas instituições) ou profissionais e em modalidades específicas de carreiras não são escolhas produzidas aleatoriamente e de maneira independente do "ponto de partida" das trajetórias. Antes disso, é preciso buscar a base das libidos aos posicionamentos políticos e dos espaços de possiveis disponíveis aos diferentes protagonistas das disputas políticas. A partir de então, podemos refletir sobre outras bases de inscrição que condicionam os caminhos e chegadas de agentes posicionados no topo da pirâmide política e que conquistam multinotabilidades.

7. Sobre o primeiro padrão, remetemos aos estudos sobre Minas Gerais de Canêdo (1998); sobre o Ceará de Barreira (2006); e o prolongamento dessa pesquisa tomando, comparativamente, o caso maranhense (Grill, 2009). O cotejamento do segundo padrão com os estudos sobre descendentes de imigrantes são reveladores de fatores comuns de reprodução de "famílias na política". Grifamos as pesquisas de Fausto et al. (1995), em São Paulo; Seyferth (1999), em Santa Catarina; e Grill (2009), no Maranhão. Já no que tange ao terceiro padrão, podemos considerar as semelhanças desse perfil de "família de políticos" com aqueles descritos por Kuschnir (2000), para o Rio de Janeiro. 


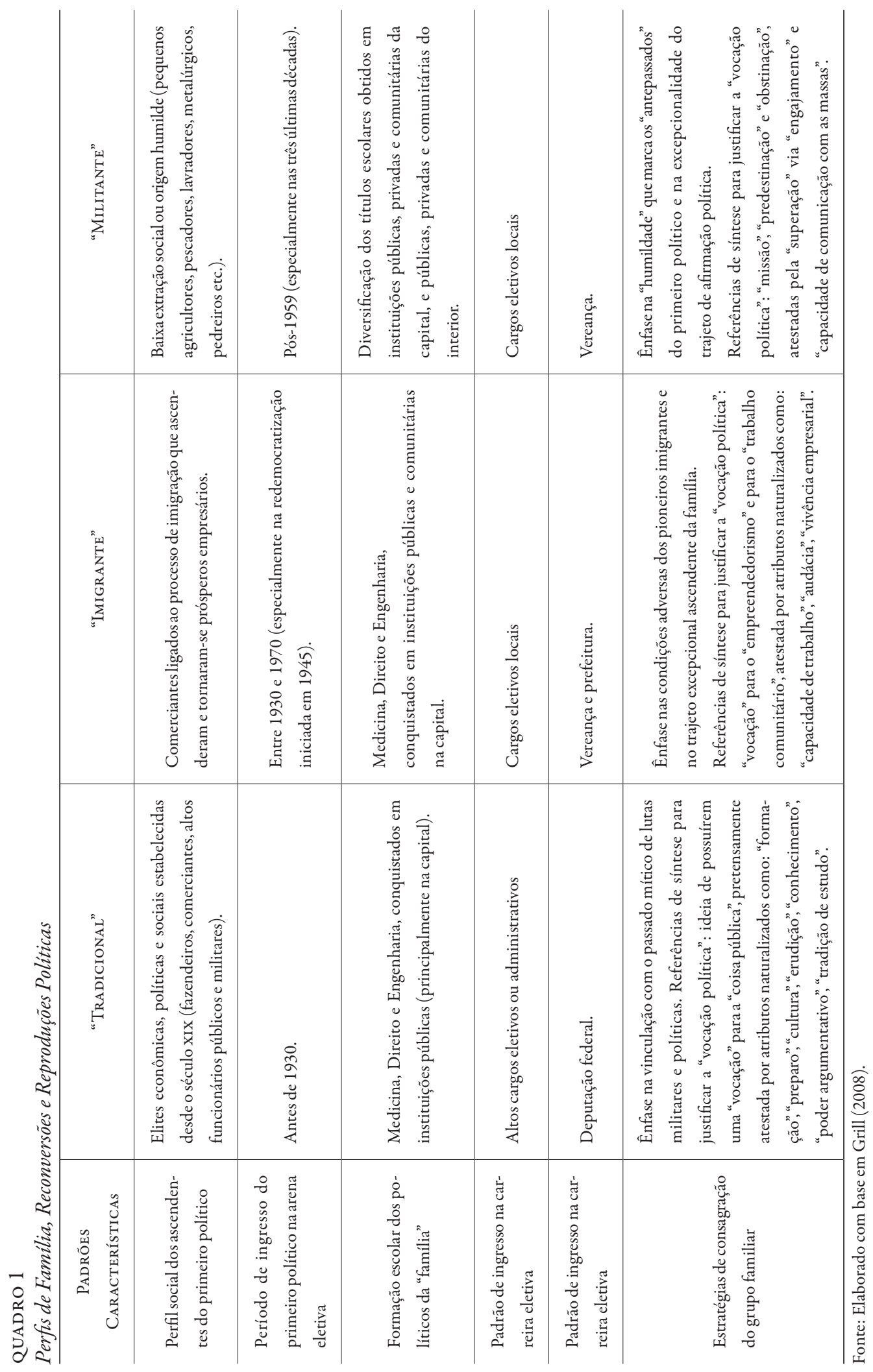

146 Tempo Social, revista de sociologia da USP, v. 29, n. 3 


\section{Carreiras e destinos políticos}

Para este momento da discussão, a noção de carreira assume centralidade por indicar a opção pelo tratamento processual e diacrônico dos desdobramentos das apostas feitas por agentes desde suas entradas na política (Offerlé, 1996). Portanto, ela comporta uma dimensão temporal de análise das trajetórias com base na qual podemos apreender os diferentes momentos, multiplicidades e variações das modalidades de atuação dos agentes, dos domínios sociais privilegiados, das relações que estabelecem ou desfazem, e dos trunfos que acionam, valorizam ou descartam. Por esse intermédio, podemos detectar modificações ou constâncias nos princípios de apreciação daquilo que é tido como predicado ou atributo almejado (logo, disputado), bem como a sua tradução em critérios de hierarquização nos domínios políticos. Combinado a uma abordagem sincrônica, é possível perceber mais detidamente os conteúdos atribuídos, as identificações construídas e os constrangimentos emergentes nas sucessivas configurações às quais pertencem (ajudam a tecer e se submetem). Situamos, assim, os sistemas (móveis) de posições ocupadas pelos agentes e compreendemos os fundamentos de suas tomadas de posição.

Discutimos anteriormente como os condicionantes sociais, apreendidos a partir das origens familiares, constituem disposições (no duplo sentido do termo) para agentes investirem suas energias em determinadas direções, como a do engajamento político. É claro que no decorrer de suas biografias (relacionalmente definidas em função dos sistemas de interação com outros agentes e domínios) são redefinidos os sentidos de satisfação, as expectativas, as avaliações prospectivas etc., assim como os recursos passíveis de serem mobilizados visando conquistar ou preservar certas posições. Lembrando que a compreensão das estratégias (não necessariamente racionalizadas) propulsoras de dirigentes políticos não deve perder de vista os mecanismos históricos e sociais que condicionam lógicas de classificação, desclassificação e reclassificação de agentes e de gerações, que pesam sobre os seus "destinos" (Bourdieu, 1998).

Não raro, as lideranças políticas tiveram biografias militantes antes de ingressar na vida adulta e no jogo político partidário e eleitoral (sabemos que essas chances aumentam quando elas são oriundas de famílias com algum tipo de vinculação política). Geralmente a estreia na intervenção política mais sistemática (para "herdeiros" ou não) acontece no meio estudantil (secundarista ou universitário) e que, afora a aquisição ou exposição de um savoir faire militante, proporciona a construção de identificações que podem ser relativamente duradouras, podendo-se observar seus prolongamentos ou interrupções nas carreiras profissionais e políticas. De qualquer modo, os desdobramentos dos engajamentos são tributários da articulação entre as imposições e os ritmos das trajetórias individuais com as configurações históricas 
e políticas que oportunizam ou obstruem determinadas modalidades e repertórios de mobilização. Consequentemente, interferem na qualificação/desqualificação de certos trunfos e nas chances dos agentes traçarem carreiras militantes relativamente "bem sucedidas" ou das mesmas serem eclipsadas ou interrompidas (Juhem, 2001) ${ }^{8}$.

Quando o engajamento inaugural ocorre em períodos caracterizados como de crise política, nos termos definidos por Dobry (1992), as fontes de créditos excepcionais são potencializadas, proporcionalmente às apostas feitas e aos riscos corridos. As teias de relações estabelecidas são passíveis de serem mobilizadas no decurso das trajetórias dos agentes, em diferentes circunstâncias e em distintos pontos do espaço social, afora as experiências, aprendizados, disputas e recordações que podem forjar sentidos de contemporaneidade e elos "geracionais", reforçados e recriados na constante reinvenção das singularidades históricas e biográficas.

Esses apontamentos estão apoiados na pesquisa dos militantes que atuaram em movimentos de resistência ao regime militar entre 1960 e 1970, na qual procuramos apreender não somente as lógicas e modalidades de engajamentos militantes, como também as condições de reconfiguração de perfis, espaços e repertórios de intervenção política no Rio Grande do Sul. Para tanto, utilizamos fontes diversas (documentos, panfletos, atas, boletins, livros, biografias etc., produzidos à época e no decorrer dos itinerários individuais e coletivos) e reunimos informações sobre 429 militantes (atuantes no movimento estudantil, secundarista e universitário, em diferentes organizações clandestinas e no MDB), sistematizadas em um banco de dados. Também foram feitas 62 entrevistas em profundidade com personagens desse universo mais amplo que se destacaram nos domínios políticos e culturais do estado (Reis, 2015).

No que diz respeito aos estudos de elites políticas em pauta neste artigo, o exame das posições sociais e políticas ocupadas pelos agentes ao longo das suas biografias militantes, em consonância com as características sociais dos mesmos e as conjunturas, permite-nos apreender os fatores interdependentes que incidem sobre processos de seleção política. Nesse caso, foram testadas basicamente seis variáveis: (1) a origem social; (2) o nível de adesão às "causas" e "organizações" nos anos de 1960 e 1970; (3) o investimento "cultural"; (4) o investimento em títulos escolares; (5) o uso da biografia militante; e (6) a dependência posterior em relação aos vínculos e contatos constituídos no período inaugural do engajamento político.

Correlacionando-as, identificamos algumas modalidades de carreiras seguidas. Sintetizamos no Quadro 2 três padrões que nos parecem pertinentes à análise. Grosso modo, vemos que no primeiro há um alto nível de adesão às “causas” e às “organiza-

8. Para um balanço sobre os usos na sociologia política francesa da noção de carreira em estudos sobre o engajamento militante, ver Sawicki e Siméant (2011). 


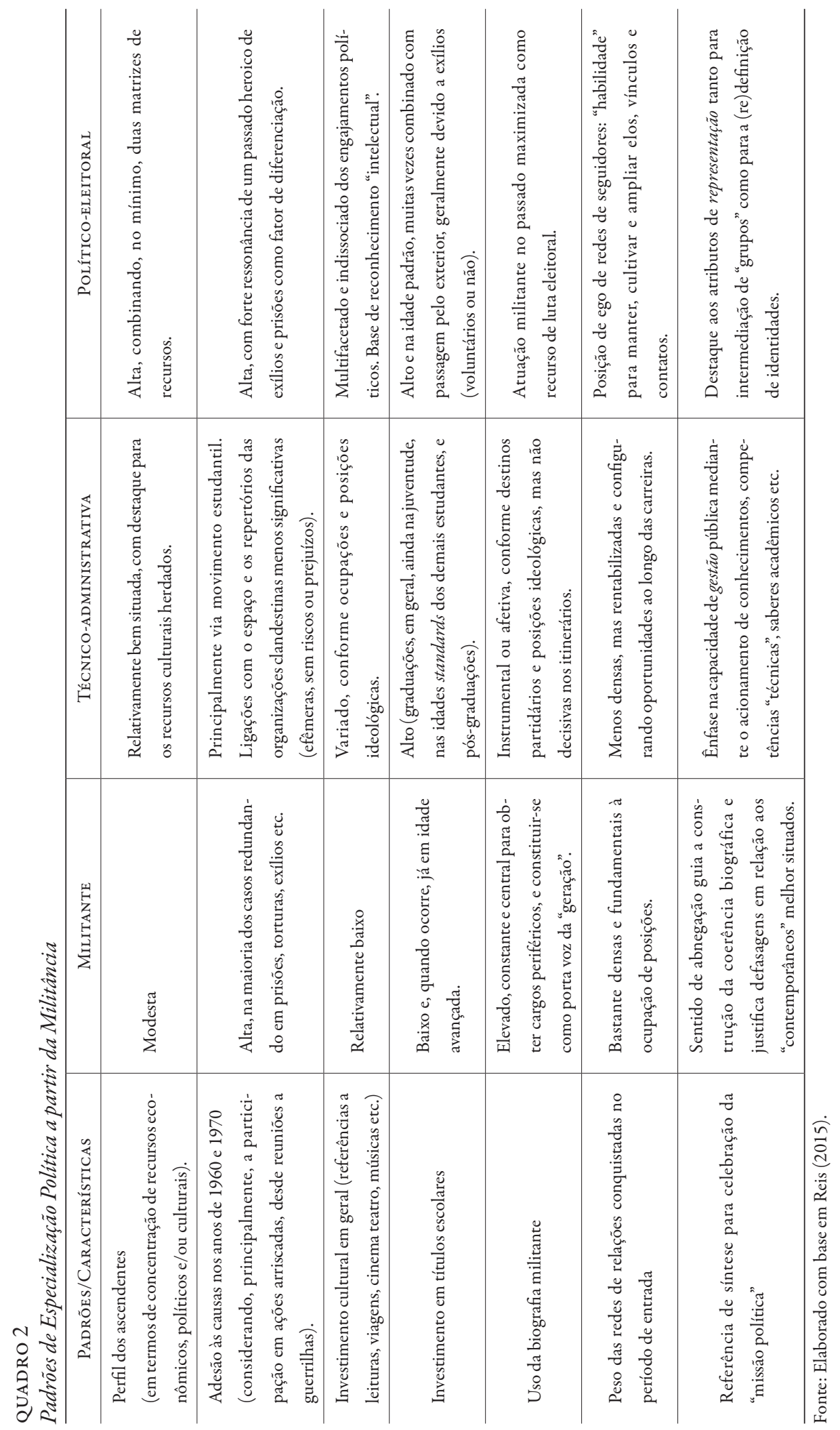


ções" durante o "regime militar" e posterior uso da biografia militante, bem como uma significativa dependência em relação aos laços constituídos naquele momento. A origem social tende a ser mais modesta e o investimento cultural menos significativo. No segundo, há um forte investimento escolar, menor uso da biografia militante e o alto peso das redes de relações. Esse padrão de carreira tende a se desdobrar em dois polos. Um que se caracteriza pela origem social, nível de adesão nos anos inaugurais e investimentos culturais mais baixos em relação aos demais. As carreiras dos agentes seriam então marcadas pela ocupação de cargos intermediários em governos, partidos e assessorias de mandatos. E, no outro polo, estão localizados os agentes com origem social mais alta, assim como seriam mais altos os níveis de adesão e de investimentos culturais. Por conseguinte, no decorrer das suas carreiras conseguem ocupar cargos de destaque. Adiciona-se a isso que, não raro e dependendo de outros investimentos, os agentes que seguiram nessa rota estão mais próximos do espaço acadêmico, inscrição esta que permite a conservação e renovação de atributos de gestão. E o terceiro padrão, de carreiras político-eleitorais, tende a comportar altos índices na origem social dos agentes, no grau de adesão e de atuação no momento inaugural de engajamento político, no investimento cultural, no investimento escolar e no uso das redes de relações estabelecidas ao longo dos trajetos.

O que diferencia o "padrão político-eleitoral" da modalidade "técnico-administrativa" é que entre os primeiros é possível verificar em detalhe vetores de personificação/pessoalização das qualidades de liderança política. Quer dizer, a singular relevância da atestação de uma atuação militante "excepcional" no passado e sua mobilização posterior, sobretudo com vistas ao reconhecimento do papel de mediação que eles conquistaram, são agregadas ao sentimento de terem incorporado disposições políticas e culturais herdadas do meio familiar e à habilidade de centralizar pessoalmente cadeias de seguidores. Ao passo que, para os últimos, quando se pensa nas propriedades dos agentes que conquistaram cargos de maior destaque ou “alto escalão”, sobressai-se o indispensável investimento e manipulação do título escolar e a menor visibilidade no domínio político.

De qualquer modo, nessas duas modalidades de carreiras podemos localizar investimentos específicos dos agentes no sentido de sustentar seus posicionamentos políticos com a mobilização de recursos culturais (não somente escolares) e obter

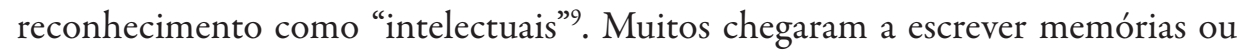
outros tipos de livros sobre suas biografias ou sobre temáticas atinentes à "luta contra

9. E na pesquisa também foi constatado o inverso, ou seja, agentes que seguiram carreiras basicamente acadêmicas retiram de modo decisivo créditos da sua atuação militante inaugural e da persistência de tipos variados de intervenção política, mesmo que não partidárias e eletivas, mas consoantes com as possibilidades, não raras, de ocupação de cargos administrativos. 
a ditadura" e correlatas. Mas escreveram sobre outros assuntos, assim como políticos de diferentes gerações, filiações etc. investiram igualmente na publicação de textos, em geral, e de livros, em particular. $O$ fato é que o trabalho de manipulação de bens simbólicos não é insignificante nas batalhas pelas definições legítimas do mundo social, particularmente nas competições políticas, para as quais a legitimidade do "representante" depende das representações sobre o trabalho de representação, sobre a política, a sociedade, os intelectuais etc.

\section{Intersecções entre domínios políticos e culturais}

Coradini (2004, p. 220) apontou como o "engajamento em diferentes esferas de militância e mediação social e cultural" (não necessariamente de "esquerda") tem peso crucial na constituição de um capital de relações sociais (quase sempre extensivo daquele oriundo do grupo familiar) imprescindível à ocupação de determinadas posições no âmbito político-partidário e profissional. Tais relações são imperativas (independentemente do enraizamento), porém os agentes são mais ou menos dependentes das teias sociais conforme a posse de outros atributos "qualificados" ao favorecimento de trânsitos e de reconhecimentos. Podemos situar o capital cultural e o reconhecimento intelectual como indicadores fortes dos êxitos sociais e políticos, assim como as inserções e identificações políticas (partidárias ou não) são proveitosas ao acesso a postos e produtos distintivos. Como já dissemos no início, nossas pesquisas têm demonstrado o trabalho ativo de elaboração de intercruzamentos entre esses créditos e lógicas como princípio gerador de posições e posicionamentos de agentes que conquistam um duplo e indissociável reconhecimento como "políticos" e "intelectuais". E devido ao alto grau de indiferenciação em tela, justificamos pensar em termos de dominios de atuação.

Há diversos amálgamas que estão na base dos investimentos e retribuições (materiais e simbólicas $)^{10}$ de agentes que ocupam multiposicionalidades e conquistam multinotabilidades. As inserções em domínios políticos são apoiadas em uma mescla de registros familiares, profissionais, sindicais, religiosos etc. Ocorrendo o mesmo para os domínios culturais, cujas fronteiras são particularmente sensíveis às adesões políticas, das quais emanam demandas de posicionamentos e as possibilidades concretas de ocupação de postos políticos. Esses processos viabilizam a ativação de mecanismos de legitimação que são indistintos aos investimentos políticos e intelectuais.

Se as relações entre "cultura" e "política" são geralmente tratadas a partir dos "intelectuais" ou seus domínios (acadêmicos, jornalísticos, jurídicos etc.), nossa 
proposta é inverter essa ênfase para examinar a afirmação de uma elite política, graças não somente ao acúmulo de recursos culturais (como os escolares e os gostos herdados ou adquiridos) ou apropriação de produtos "acabados" (literatura, ciência, filosofia, religião etc.), mas também como laboriosos geradores de bens desse tipo. Assim, podemos analisar agentes responsáveis pela produção de representações sobre o mundo social fundamentados em propriedades e saberes socialmente valorizados, levando em conta as condições de eficácia de certos discursos e as modalidades de intervenção acionadas por detentores de atributos (sociais, políticos, culturais, econômicos etc.), que garantem a autoridade legítima para participar das batalhas de manipulação de bens simbólicos.

Neste momento, destacamos a produção escrita dos políticos como particularmente emblemática da simbiose entre duas funções de representação presentes no trabalho político. Por um lado, a mediação de "grupos", "categorias”, "coletividades”, "bases eleitorais"; por outro, a definição da "nação", da "região", da "economia”, da "cultura" e da própria "política”. Ela, novamente, reflete os efeitos da preparação e do treinamento prévios em meios diversos (família, escolas, universidades, sindicatos, partidos, movimentos etc.) ao "uso da palavra" (nesse caso, escrita). Portanto, o estudo desse universo, delineado a partir dos investimentos em escrita dos agentes, permite evidenciar as bases da aquisição de uma condição de intelectual, esteada na biografia política e de porta-voz político diferenciado, justamente pela habilidade de interpretar, formular, elaborar explicações sobre o social.

As reflexões nesse caminho foram feitas mais sistematicamente ao longo de uma série de estudos que realizamos tomando como critério inicial de delimitação do universo de análise um conjunto de parlamentares brasileiros (deputados federais e/ou senadores) eleitos entre 1945 e 2010, que além de carreiras políticas longevas, também tiveram significativa publicação de livros. Com base nisso, outros recortes foram feitos em função de imbricações apuradas entre os perfis dos agentes e seus investimentos/inserções culturais (Grill e Reis, 2016).

Nosso ponto de partida foi um levantamento prévio no Dicionário histórico-biográfico brasileiro (DНВB) da Fundação Getúlio Vargas (Abreu et al., 2001), no qual localizamos 1.181 casos de parlamentares com obras publicadas citadas nos verbetes. Produzimos um banco de dados com poucas variáveis (basicamente origem geográfica, período de ocupação de cargos e gêneros de textos que publicaram ao longo das suas biografias). Procedemos à classificação das publicações (4.062 títulos) em cinco gêneros: os setorializados, que explicitam o uso de competências específicas (profissionais, militantes, escolares etc.); discussões de cunho mais generalista (edificadores de projetos de sociedade, ideologias, identidades etc.); produções literárias (romances, novelas, contos, crônicas e poesias); narrativas, descrições ou 
análises históricas sobre personagens e/ou eventos; e confissões políticas (memórias e autobiografias, sendo essas últimas muito raras).

Dessas informações observamos, entre outras coisas, que mais da metade dos agentes são oriundos dos maiores estados do sudeste e sul, seguido pela presença não negligenciável de casos provenientes de capitais do nordeste; de modo prevalecente são políticos com inserção eletiva por mais de duas décadas (sem descartar a ocupação de cargos político-administrativos); há uma maior diversidade de gêneros de escrita entre os parlamentares com atuação mais sistemática entre as décadas de 1930 e 1950; um maior volume de publicações para aqueles com destaque nas décadas de 1950 e 1960; e um arrefecimento na quantidade de publicações na forma de livros relativamente ao aumento das tomadas de posição em jornais e revistas e direcionadas a publicações mais "especializadas" entre aqueles com participações nas últimas décadas.

Alinhavada a moldura geral, aplicamos uma segunda delimitação selecionando 299 casos de agentes com intensa, persistente e relativamente equilibrada dedicação tanto à carreira política quanto à produção escrita. Procuramos refinar a análise aplicando correlações entre os gêneros de escrita e variáveis referentes aos períodos históricos (décadas de entrada na política), à posição social (mediante indicadores como títulos escolares, instituições em que foram obtidos e profissões exercidas) e à posição alcançada na hierarquia política (cargos eletivos e administrativos mais altos ocupados).

Chegamos a correspondências entre princípios de hierarquização social e de hierarquização/legitimação vigentes em domínios políticos. Há claramente conjunções entre o recrutamento em segmentos estabelecidos social e politicamente aos quais historicamente foi atribuído o papel de pensar, refletir, interpretar, decifrar "realidades"; o exercício de ocupações ligadas a saberes, competências e condições de trabalho que ao mesmo tempo predispõem e impõem a prática da escrita; a posse de títulos que certificam a fusão direito/dever de escrever; o pertencimento a "rodas" de letrados e personalidades públicas que facilitam a publicação e divulgação de obras; entre outras. Essas características denotam, portanto, a composição, no seio da elite política, de uma "nobreza" diferenciada culturalmente e bem-sucedida do ponto de vista eleitoral. Associado a isso, observa-se a consolidação do gênero setorial e o progressivo uso de conhecimentos técnicos ou especializados (voltados para a gestão e representação política); a persistência ao longo do tempo da relevância em escrever sobre as questões da atualidade (generalistas); e o declínio de gêneros como o literário e as biografias históricas, que paulatinamente são monopolizados por profissionais da literatura, história ou ciências humanas.

No Quadro 3 distribuímos algumas das características encontradas em três padrões de perfis para melhor explicitar certas alterações na composição dessa elite política que se posiciona por meio da escrita. Como já afirmamos, a maioria dos agentes têm 
origens altas, ocuparam altos cargos e investiram em inserções culturais, em especial na publicação de livros. Os "notáveis letrados" são mais frequentemente formados em direito, exerceram principalmente postos eletivos, contaram não somente com o trânsito em domínios culturais (universidades, academias de letras, institutos históricos etc.), mas ocupando posições de destaque e reconhecimento de uma condição intelectual, traduzida em publicações variadas, principalmente literária e histórica. Os "tribunos do social" são aqueles porta-vozes de questões variadas, com formações universitárias que privilegiam os cursos de ciências humanas (ou que se relacionam com essa linguagem) e alternaram a ocupação de posições eletivas e administrativas. E o último perfil, mais recentemente afirmado, é o dos "gestores do público": predominantemente com formação em economia (mesmo que adicionada a outros títulos); ocupam preeminentemente altos cargos administrativos; atuam como professores universitários; escrevem com frequência em jornais e revistas; e suas publicações são basicamente sobre os temas nos quais são considerados especialistas (ou experts).

QUADRO 3

Perfis de Parlamentares e Investimentos Culturais

\begin{tabular}{|c|c|c|c|}
\hline $\begin{array}{c}\text { Padróes } \\
\text { Características }\end{array}$ & NotÁVEIs LEtrados & TRIBUNOS DO “SOCIAL" & Gestores do "público" \\
\hline $\begin{array}{l}\text { Posição de origem dos } \\
\text { ascendentes }\end{array}$ & Alta. & Alta. & Alta. \\
\hline $\begin{array}{l}\text { Décadas de entrada na } \\
\text { política }\end{array}$ & Até os anos de 1950. & $\begin{array}{l}\text { Ao longo de todo o período } \\
(1945-2010) \text {. }\end{array}$ & $\begin{array}{l}\text { Ao longo de todo o período, } \\
\text { porém mais presentes nas últimas } \\
\text { décadas. }\end{array}$ \\
\hline Títulos escolares & Direito & Ciências humanas. & Economia. \\
\hline $\begin{array}{l}\text { Cargos mais altos ocu- } \\
\text { pados }\end{array}$ & $\begin{array}{l}\text { Até } 1950 \text { aqueles que chegavam à } \\
\text { deputação federal e ao senado; nas } \\
\text { últimas décadas mais fortes entre } \\
\text { governadores e senadores. }\end{array}$ & Deputação federal. & Ministérios e Direção de estatais. \\
\hline $\begin{array}{l}\text { Tipo de carreira política } \\
\text { (tipos de cargos mais fre- } \\
\text { quentemente ocupados) }\end{array}$ & Eletivos. & $\begin{array}{l}\text { Eletivos ou que se dividi- } \\
\text { ram ao longo do tempo } \\
\text { entre o exercício de funções } \\
\text { eletivas e administrativas. }\end{array}$ & $\begin{array}{l}\text { Administrativos ou que se divi- } \\
\text { diram ao longo do tempo entre } \\
\text { o exercício de funções eletivas e } \\
\text { administrativas. }\end{array}$ \\
\hline Inscrições culturais & $\begin{array}{l}\text { Jornais, instituições de ensino (como } \\
\text { atividade secundária) academias de } \\
\text { letras, institutos históricos etc. }\end{array}$ & $\begin{array}{l}\text { Jornais, instituições de } \\
\text { ensino (como atividade } \\
\text { secundária) academias de } \\
\text { letras, institutos históri- } \\
\text { cos etc. }\end{array}$ & $\begin{array}{l}\text { Instituições de ensino (exercendo } \\
\text { o magistério como principal } \\
\text { atividade), fundações partidárias } \\
\text { e associações profissionais. }\end{array}$ \\
\hline Gêneros de escrita & Literatura e biografias históricas & Generalista & Setorializado \\
\hline
\end{tabular}

Fonte: Elaborado com base em Grill e Reis (2016). 


\section{Considerações finais}

Neste artigo, tentamos indicar alguns encaminhamentos que consideramos relevantes aos estudos de agentes que alcançam posições de elite ou que conquistam multinotabilidades, particularmente em domínios políticos. A mobilização das noções grifadas se apoia na percepção de que, para situações marcadas por um alto grau de plasticidade das lógicas e fronteiras sociais, são adequados recursos conceituais mais gerais e plurais. Quer dizer, conceitos que, de algum modo, permitam-nos abranger a multiplicidade de segmentos ou grupos dirigentes ou dominantes (engajados em diferentes configurações históricas e sociais de luta e cujas legitimidades são sempre vulneráveis à contestação); de posições e posicionamentos desigualmente distribuídos; de perfis e trajetórias sociais, culturais e políticos; de princípios dominantes e amalgamados de percepção; de trunfos, estratégias e modalidades de atuação agilizadas; de trânsitos disponíveis e reconhecimentos assegurados.

Para demonstrar como concebemos este tratamento, apresentamos três desdobramentos desenvolvidos com base em pesquisas específicas sobre "famílias de políticos" "carreiras militantes" e "produção cultural" de agentes que se especializaram na ocupação de postos políticos eletivos e/ou administrativos. Para cada um deles, construímos três padrões de afirmação e reprodução política de famílias ("tradicional", "imigrante" e "militante"), de especialização política advinda de intervenções militantes ("militante", "técnico-administrativo" e "político-eleitoral”) e de perfis parlamentares interseccionados à produção escrita ("notáveis letrados", "tribunos do social" e "gestores públicos").

$\mathrm{Na}$ análise do conjunto dos perfis de profissionais da política expostos, evidenciamos, entre outros aspectos, que os recursos acumulados pelos agentes dependem de modo significativo da sua capacidade de personificar e até incorporar reputações, notoriedades e estimas ligadas a "nomes de família", "títulos" (escolares e profissionais), protagonismos em eventos históricos, autorias de publicações, entre outros. Principalmente, têm relevo as demonstrações pessoais e pessoalizadas, que atestem honorabilidades e que revelem a habilidade de mediação entre gerações, entre períodos históricos, entre domínios (políticos, culturais, econômicos, religiosos, étnicos etc.), entre instâncias, enfim, múltiplos e complementares pertencimentos que os autorizam à dupla e indissociável condição de porta-voz e de intérprete. 


\section{Referências Bibliográficas}

Abreu, Alzira A. et al. (orgs.). (2001), Dicionário histórico-biográfico brasileiro pós-30. Rio de Janeiro, Editora da FGV.

BArreira, Irlys. (2006), “Campanha em família: as veias abertas das disputas eleitorais”. In: Palmeira, Moacir \& Barreira, Cesar. Politica no Brasil: visóes de antropólogos. Rio de Janeiro, Relume Dumará, pp. 301-332.

Bourdieu, Pierre. (1994), "Stratégies de reproduction et modes de domination”. Actes de la Recherche en Sciences Sociales, 1 (105): 3-12. . (1996), “O espírito de família”. In: Razões práticas. Campinas, Papirus. . (1998), “Classificação, desclassificação, reclassificação”. In: Nogueira, M. A. \& Catani, A. (orgs). Bourdieu, escritos de educação. Petrópolis, Vozes, pp. 145-183. . (2004), Ofício do sociólogo. Petrópolis, Vozes.

Braud, Philippe. (2001), La science politique. Paris, PUF.

Briquet, Jean-Louis. (1992), “Une histoire de famille”. In: Patriat, Claude \& Parodi, Jean-Luc (orgs.) L'HÉRÉDITÉ en politique. Paris, Economica, pp. 1-22.

CANÊDo, Letícia B. (1998), "La production génèalogique et les modes de transmission d'un capital politique familial dans le Minas Gerais brésilien”. Genèses, 31: 4-28.

Cohen, Antonin et al. (2009), “Qu'est-ce que la science politique?”. In: (orgs.). Nouveau manuel de science politique. Paris, La Découverte, pp. 21-34.

Coradini, Odaci L. (2001), Em Nome de Quem? Recursos sociais no recrutamento de elites politicas. $1^{\mathrm{a}}$ ed. Rio de Janeiro, Relume Dumará/UfrJ. . (2004), "A formação e a inserção profissional dos professores de ciências sociais no Rio Grande do Sul”. In: Almeida, Ana Maria F. et al. (orgs.). Circulação internacional e formação intelectual das elites brasileiras. Campinas, Editora da Unicamp, pp. 213-240. . (2016), “As elites como objeto de estudo, novamente”. In: Reis, Eliana Tavares dos \& GRILl, Igor Gastal. Elites politicas e culturais: reflexões e aplicações não canônicas. São Luís, EDUFMA pp. 127-140.

Dobry, Michel. (1992), Sociologie des crises politiques. Paris, Presses de la Fondation Nationale des Sciences Politiques.

Elias, Norbert. (1993), O processo civilizador. São Paulo, Jorge Zahar Editor, vol. 2. . (1994), Sociedade dos indivíduos. São Paulo, Jorge Zahar Editor.

Fausto, Boris et al. (orgs.). (1995), Imigração e politica em São Paulo. São Paulo, Sumaré.

FAVRE, Pierre. (1989), “Quelques considérations sur la démarche et les finalités de l'enseignement de la science politique”. Favre, Pierre \& Lagavre, Jean- Baptiste. (dirs.). Enseigner la science politique. Paris, L'Harmattan, pp.15-36.

Gaxie, Daniel. (2005), “Rétribuitions du militantisme et paradoxes de l'action collective”. Swiss Polical Science Review, 1 (11): 157-188. 
GRILL, Igor Gastal \& REIs, Eliana Tavaras dos. (2016), Elites parlamentares e a dupla arte de representar. Rio de Janeiro, Editora da FGV.

GRILL, Igor Gastal. (2009), “Descendentes de imigrantes na política do Rio Grande do Sul e do Maranhão: ascensão social, afirmação eleitoral e cooptação política”. In: FERRETTI, Sérgio \& Ramalho, José Ricardo. Amazônia: desenvolvimento, meio ambiente e diversidade sociocultural. São Luís, EDUFMA, pp. 137-160. . (2008), Heranças politicas no Rio Grande do Sul. São Luis, Edufma.

GrynszPan, Mario. (2016), "Do pessimismo ao pluralismo: apropriações da teorias das elites nos Estados Unidos". In: ReIs, Eliana Tavares dos \& GRILL, Igor. Elites politicas e culturais: reflexões e aplicações não canônicas. São Luís, EDUFMA, pp. 49-80.

. (1999), "La théorie des élites aux États-Unis: conditions sociales de réception et d'appropriation". Genèses, 37: 27-43.

Juhem, Philippe. (2001), "Entreprendre en politique: les carrières militantes des fondateurs de sos-Racisme". Revue Francaise de Science Politique, 1-2 (51): 131-153.

Kuschnir, Karina. (2000), O cotidiano da politica. Rio de Janeiro, Jorge Zahar.

MARENCO dos SANTos, André. (2004), "Le renouveau politique: carrières politiques et liens de parti au Brésil (1946-2002)”. Politique et Sociétés, 2/3 (23): 9-133.

Offerlé, Michel. (1996), “Entrées en politique”. Politix, 35: 3-5.

Perissinotto, Renato \& Miriade, Angel. (2009), "Caminhos para o parlamento: candidatos e eleitos nas eleições para deputado federal em 2006”. Dados, 52: 301-333.

Politix. (2004), “Dossier: Trajectoires de la notabilité”. Politix: Revue des Sciences Sociales du Politique, 67 (17).

ReIs, Eliana Tavares dos (2015), Trajetórias, espaços e repertórios de intervenção política. Porto Alegre/São Luís, zouk/EDufMa.

ReIs, Eliana Tavares dos \& GRILL, Igor Gastal. (2016), "Mirada reflexiva e esforços propositivos às pesquisas sobre elites". In: Elites políticas e culturais: reflexões e aplicações não canônicas. São Luís, EDUFMA, pp. 9-48.

Rocha, Daniella N. C. (2009), "Les jeunes du Parti des Travailleurs à 1 épreuve de la crise du militantisme? Modalités de socialisation et carrières militantes des jeunes petistas de Brasilia hier et aujourd hui". Agora: Debat Jeunesses, 51: 89-104.

Rodrigues, Leôncio M. (2002), Partidos, ideologia e composição social. São Paulo, Edusp.

Ruget, Vanessa. (2009), “La science politique aux États Unis et em Europe”. In: Cohen, Antonin et al. (orgs.). Nouveau manuel de science politique. Paris, La Découverte, pp. 28-29.

SaWiCKi, Frédéric \& Simeant, Joana. (2011), "Inventário da sociologia do engajamento militante: nota crítica sobre algumas tendências recentes dos trabalhos franceses". Sociologias, 28(13): 200-255.

. (1999), "Classer les hommes politiques. Les usages des indicateurs de position sociale 
pour la compréhension de la professionnalisation politique”. In: Offerlé, Michel. La profession politique XIX-XX siècles. Paris, Belin, pp. 135-170.

Seyferth, Giralda. (1999), "Etnicidade, política e ascensão social: em exemplo teuto-brasileiro". Mana. 2 (5).

Weber, Max. (1987), Economia y sociedad. México, Fondo de Cultura Económica.

Wolf, Eric. (2003), "Parentesco, amizades e relações patrono-cliente em sociedades complexas". In: Ribeiro, Gustavo Lins \& Bianco, Bela Feldman (orgs.). Antropologia e poder: contribuições de Eric R. Wolf. Brasília/São Paulo/Campinas, Editora da UnB, Imprensa Oficial, Editora da Unicamp, pp. 93-114. 


\section{Resumo}

Estudos de elites políticas e as bases das multinotabilidades no Brasil

Este artigo discute três bases de multinotabilização das elites políticas (a familiar; a militante e profissional; a produção de bens simbólicos) e como se traduzem em trunfos mobilizáveis nas lutas políticas no Brasil. Mediante reflexão indissociavelmente analítica e empírica, propomos que a apreensão das multidimensionalidades e das intersecções entre domínios e práticas potencializa a investigação extensiva e intensiva dos princípios de funcionamento, de seleção e de hierarquização políticas, dos condicionantes e lógicas de atuação dos agentes, bem como dos processos de legitimação que incidem na composição dos profissionais da representação.

Palavras-chave: Elites, Política, Multinotabilidades, Carreiras, Brasil.

\section{Abstract}

Studies of political elites and the bases of multinotabilities in Brazil

This article discusses three bases for political elites' multinatobilization (family, militant and professional, production of symbolic goods) and how they translate into usable trumps in Brazilian political struggles. From an analytical and empirical reflection, we propose that the apprehension of its multiple dimensions and the intersections between domains and practices may lead to an extensive and intensive investigation of political functioning principles, selection and hierarchization, of the agents' conditioning and logics, as well as of the legitimacy processes that affect the composition of these representation professionals.

Keywords: Elites, Politics, Multinotabilities, Careers, Brazil.

Texto recebido em 30/1/2017 e aprovado em 29/5/2017. DoI: 10.11606/0103-2070. ts.2017.125888.

ELIANa TAVARES Dos Reis é professora/pesquisadora do Programa de Pós-graduação em Ciências Sociais da Universidade Federal do Maranhão e coordenadora do Laboratório de Estudos sobre Elites Políticas e Culturais (LEEPOC).E-mail: eliana1 reis@terra.com.br.

IGOR GASTAL GRILL é professor/pesquisador do Programa de Pós-graduação em Ciências Sociais da Universidade Federal do Maranhão e coordenador do Laboratório de Estudos sobre Elites Políticas e Culturais (LEEPOC).E-mail: igorgrill@terra.com.br 